\title{
Rockall Score Larger Than 7 as a Reliable Criterion for the Selection of Indications for Preventive Transarterial Embolization in a Subgroup of High-Risk Elderly Patients After Primary Endoscopic Hemostasis for Non-Variceal Upper Gastrointestinal Bleeding
}

\author{
Aleksejs Kaminskis ${ }^{\mathrm{a}}$, ${ }^{\text {, Patricija Ivanova }}{ }^{\mathrm{b}}$, Sanita Ponomarjova ${ }^{\mathrm{b}}$, \\ Maksims Mukans ${ }^{\mathrm{c}}$, Viesturs Boka ${ }^{\mathrm{d}}$, Guntars Pupelis ${ }^{\mathrm{e}}$
}

\begin{abstract}
Background: Transarterial embolization (TAE) is an alternative procedure to repeat endoscopy or surgical intervention in the case of rebleeding after primary endoscopic treatment. The aim of the study was to assess the Rockall score as a criterion for TAE in the case of re-bleeding after endoscopic treatment of non-variceal upper gastrointestinal bleeding (NVUGIB).
\end{abstract}

Methods: Out of the 673 patients who underwent emergent endoscopic hemostasis due to NVUGIB, 111 had a high risk of re-bleeding having a Forrest I-IIb ulcer and the Rockall score $\geq 5$. From 111 patients, 37 accepted preventive TAE ( $\mathrm{PE}+$ group). The control group consisted of 74 patients who underwent standard treatment (PEgroup).

Results: There were no differences in the demographic status between both groups, nor in the main clinical data on admission. The performance of TAE resulted in a significantly lower re-bleeding rate ( $1(4.8 \%)$ vs. $11(33 \%), \mathrm{P}=0.018)$. No patient who underwent TAE with the Rockall score $\geq 7$ required surgery, resulting in only one rebleeding episode $(\mathrm{P}=0.004)$. Mortality reached $5 \%$ and $11 \%$ in the $\mathrm{PE}+$ and $\mathrm{PE}-$ groups accordingly.

Conclusion: The Rockall score $\geq 7$ could be a reliable predictor of re-bleeding after primary endoscopic hemostasis as one criterion for

Manuscript submitted September 20, 2017, accepted October 19, 2017

aDepartment of General and Emergency Surgery, Riga East University Hospital, Riga, Latvia

bepartment of Interventional Radiology, Riga East University Hospital, Riga, Latvia

${ }^{\mathrm{c} S t a t i s t i c a l ~ U n i t, ~ R i g a ~ S t r a d i n s ~ U n i v e r s i t y, ~ R i g a, ~ L a t v i a ~}$

${ }^{\mathrm{d}}$ Latvian University, Riga, Latvia

eSurgical Department, Riga East University Hospital, Riga, Latvia

${ }^{f}$ Corresponding Author: Aleksejs Kaminskis, Riga East University Hospital, 2

Hipokrata Str. Riga, Latvia. Email: Aleksejs.kaminskis@aslimnica.lv

doi: https://doi.org/10.14740/gr909w the selection of indications for preventive TAE.

Keywords: Non-variceal upper gastrointestinal bleeding; Preventive embolization; Risk assessment; Rockall score

\section{Introduction}

Endoscopic hemostasis is associated with an increased risk of re-bleeding in patients with severe comorbid conditions who take routine medication that may interfere with the clotting system and are poor candidates for surgical treatment $[1,2]$. The prevention of re-bleeding is, therefore, crucial in the treatment of non-variceal upper gastrointestinal bleeding (NVUGIB) due to a considerable increase in mortality in the case of failure. Transarterial embolization (TAE) as a therapeutic treatment of hemostasis has been reported to be a safe option for the management of upper gastrointestinal bleeding that is refractory to endoscopic hemostasis [3]; however, the definition of indications for TAE is still obscure, and a second endoscopic approach in the case of repeated bleeding is recommended [1, 2]. Preventive TAE is even more controversial in this high-risk group of patients [4]. Different risk scoring systems have been applied for a clearer selection of patients who are candidates for repeat endoscopic hemostasis or TAE, or even the surgical approach $[1,2]$. In recent years, the Blatchford and Rockall scores have been routinely used in our institution due to a high flux of patients with NVUGIB including a significant proportion of elderly patients with comorbid conditions who regularly use non-steroidal anti-inflammatory medication, aspirin and other medication that interferes with the clotting system [5]. Our institution runs a 24/7 emergency admission with a roundthe-clock endoscopy and interventional radiology services. If the patient is admitted in the daytime, TAE can be performed the same day; if the patient is admitted in the evening, TAE can be performed the following day. The aim of our study was to assess the clinical efficiency of the full Rockall score in the selection of patients who are at a high risk of re-bleeding after 
Table 1. Patient Characteristics

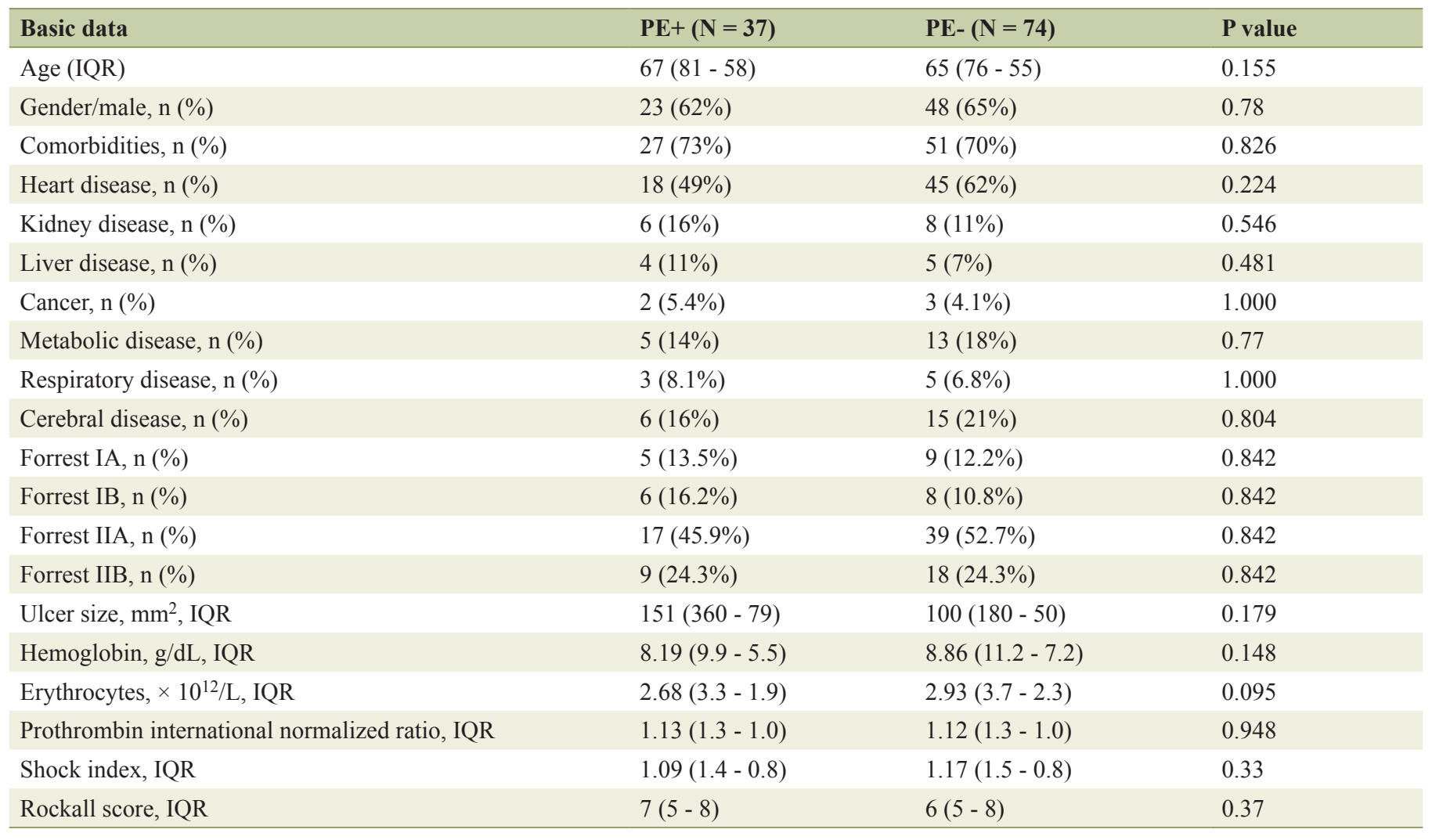

primary endoscopic hemostasis and are candidates for preventive TAE.

\section{Materials and Methods}

The preparation of the study included an analysis of the medical charts of 673 patients who were emergently admitted to the Riga East University Hospital with NVUGIB in the period from January 2010 to March 2017. Patients with an unsuccessful primary endoscopic hemostasis, or who showed re-bleeding 2 - $3 \mathrm{~h}$ after endoscopy, and where invasive radiology was not technically possible were excluded from the current study. The Rockall score was developed to define the risk of death, and has been used for other end-points including re-bleeding, duration of admission and the need for intervention (e.g. endoscopy or operative surgery).

The clinical Rockall score in our study was calculated on the basis of clinical variables (age, the presence of shock, and medical co-morbidity) at the time of presentation with the maximum of 7 points. The complete Rockall score was calculated by adding the endoscopic criteria to predict the risks of re-bleeding and death to the clinical Rockall score [5]. Due to the exclusion of patients with malignancies, the complete Rockall score was of maximum 10 points in our cohort. The results of the previous study [6] suggested that the patients with NVUGIB who were at a high risk of re-bleeding after emergent endoscopic hemostasis had a Forrest I-IIb type ul- cer and the Rockall score $\geq 5$. Preventive visceral angiography and TAE were performed on patients with acute NVUGIB who were considered to be at a high risk of recurrent bleeding after endoscopic hemostasis (PE+ group). The control group consisted of similar patients who only underwent endoscopic hemostasis or did not agree to undergo preventive TAE with a similar prognosis of high re-bleeding risk and similar comorbid conditions (PE- group). The participants were enrolled and assigned their treatment by a consensus among the consultant surgeon, consultant radiologist and duty endoscopy specialist. Endoscopic combination therapy (injection of diluted adrenaline $1: 10,000$, treatment with a heater probe, and/or hemoclip) followed by a $72-\mathrm{h}$ infusion of esomeprazole ( $80 \mathrm{mg}$ bolus followed by $8 \mathrm{mg} / \mathrm{h}$ ) was applied to all patients. All patients were closely monitored at ICU.

\section{Technical approach}

TAE was performed by the invasive radiologist. The technical goal was a preventive embolization of the left gastric artery or the gastroduodenal artery (depending on the ulcer localization) within $24 \mathrm{~h}$ of endoscopic hemostasis, achieving a decrease of the arterial flow in the tissue beneath the ulcer. In cases with the ulcer localized in the smaller or greater curvature or the gastric fundus, the left gastric artery was obliterated; in cases of gastric antral, pyloric or duodenal ulcers, the gastroduodenal artery was embolized. If 
Table 2. Distribution of Rockall Score

\begin{tabular}{lll}
\hline Variables of the clinical Rockall score & PE+ $(\mathbf{N}=\mathbf{3 7})$ & PE- $(\mathbf{N}=\mathbf{7 4})$ \\
\hline Age $<60, \mathrm{n}(\%)$ & $10(27 \%)$ & $28(38 \%)$ \\
Age $60-79, \mathrm{n}(\%)$ & $17(46 \%)$ & $34(46 \%)$ \\
Age $>80, \mathrm{n}(\%)$ & $10(27 \%)$ & $12(16 \%)$ \\
No major comorbidity, n (\%) & $13(35 \%)$ & $20(27 \%)$ \\
Other comorbidities, n (\%) & $15(41 \%)$ & $38(52 \%)$ \\
Liver, kidney cancer, n (\%) & $9(24 \%)$ & $15(21 \%)$ \\
Hemodynamically stable, $\mathrm{n}(\%)$ & $10(27 \%)$ & $37(50 \%)$ \\
Tachycardia, n (\%) & $17(46 \%)$ & $22(30 \%)$ \\
Low SBP and tachycardia, n (\%) & $10(27 \%)$ & $15(20 \%)$ \\
\hline
\end{tabular}

SBP: systolic blood pressure.

therapeutic endoscopy was insufficient to control the bleeding (technically difficult primary therapeutic endoscopy or signs of exsanguination), TAE or surgical hemostasis could be performed without being preceded by repeat endoscopy. The complication rate, recurrence of bleeding, and the need for repeat endoscopic therapy or surgery were the variables for the statistical analysis in groups. Hospital stay, including the duration of the intensive care stay, and in-hospital mortality rate among the groups were analyzed. The study was approved by the local research ethics committee and followed the Declaration of Helsinki. All authors had access to the study data and have reviewed and approved the final manuscript.

\section{Statistical analysis}

Interval data are presented in median with interquartile range (IQR). A comparison of interval data in embolization and control groups was performed with the Mann-Whitney U test, while the nominal data comparison was performed by the Pearson $\chi^{2}$ test and Fisher's exact test. Correlation with clinical data was done by the Spearman rho method. A logistic regression analysis was performed to reveal factors associated with poor outcomes. $\mathrm{P}<0.05$ was considered as statistically significant with a confidence interval of $95 \%$. Statistical analysis was performed with the SPSS version 22.

\section{Results}

In total, 111 patients had a Forrest I-IIb type ulcer and the Rockall score $\geq 5$, and were considered to be at a high risk of re-bleeding after primary endoscopic hemostasis. Preventive embolization was performed in 37 patients (PE+ group); 74 patients, on whom preventive embolization was not performed, served for control. The median age of patients was within the range of 67 - 65 years. There was no difference in gender and comorbid conditions, including the presence of cancer, liver and pulmonary diseases, which were rare in both groups (Table 1). Endoscopic findings were not different, with the median ulcer size of $100-151 \mathrm{~mm}^{2}$. The most commonly found ulcers were Forrest IIa type ulcers. The distribution of the Forrest grade was even (Table 1). The median hemoglobin level on admission was 8.19 and $8.86 \mathrm{~g} / \mathrm{dL}$ in the respective groups, the erythrocyte count was $2.68 \times 10^{12} / \mathrm{L}$ and $2.93 \times 10^{12} / \mathrm{L}$, and the Rockall score was 7 and 6 accordingly (Table 1). The variables of the Rockall score were distributed evenly (Table 2). Transfusion support was needed for the majority of patients using, on average, 4 units of packed red blood cells (PRBC) in both groups. A trend, while not significant, was observed regarding the need for more fresh frozen plasma (FFP) in the PE- group $(\mathrm{P}=0.06)$. The re-bleeding rate was significantly lower in the $\mathrm{PE}+$ group $(4(11 \%)$ vs. $20(27 \%)$ in the PE- group, $\mathrm{P}=0.047$, Table 3$)$. In the same way, surgical treatment as a repeated attempt of hemostasis was performed significantly less often in patients who underwent embolization (1 (2.7\%) vs. $17(23 \%)$ accordingly, $\mathrm{P}=0.017)$. The median ICU stay was 3 days, and the hospital stay lasted $7-8$ days in both groups. In the PE+ group, mortality reached $5 \%$, while in the PE- group, it was $11 \%$, although not reaching a statistically significant difference (Table 4).

\section{Correlation analysis}

Preventive embolization had a weak correlation with admission to ICU $(r=0.224, P=0.018)$. A statistically significant correlation was not revealed between the two patient groups considering the required transfusion of PRBC, except FFP transfusion. There was a weak negative correlation between the patient group that did not undergo preventive TAE and the required transfusion of FFP $(r=-0.223, P=0.05)$. Surgical intervention and postoperative re-bleeding rate had a weak correlation with the PE- group $(r=-0.297, \mathrm{P}=0.008$ and $r=-0.19, P=0.05)$. The analysis did not reveal a statistically significant correlation between the length of hospital stay and mortality rate. No factors were independently associated with bleeding (Table 5). The highest odds ratio was associated with the Forrest classification and the Rockall score. Due to the fact that all patients had endoscopic evidence of bleeding and ulcer as the source of bleeding that corresponds to 3 points on the Rockall score, the full Rockall score was generally dependent on the scoring of the clinical part. An 
Table 3. Need for Transfusion Support and Re-Bleeding Rate

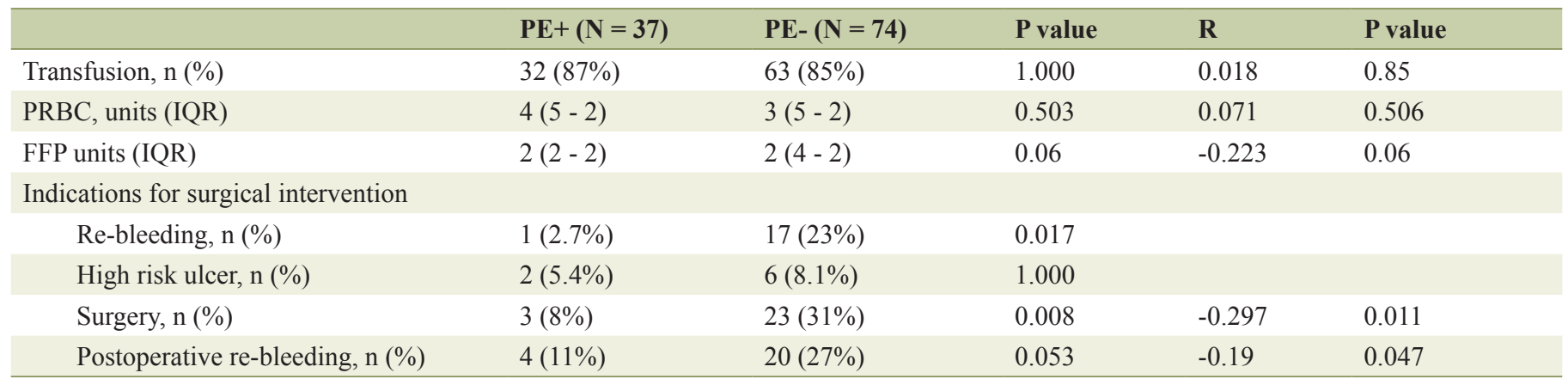

RBC: packed red blood cells; FFP: fresh frozen plasma.

additional analysis of the distribution of the Rockall score revealed that the majority of patients in both groups had a Rockall score of 7 or more, including the majority in the PE+ group. From those patients with the Rockall score 7 or more who underwent preventive embolization, no one was operated $(\mathrm{P}=0.004)$. Only one patient experienced re-bleeding after embolization, compared to $11(33 \%)$ after surgical intervention ( $\mathrm{P}=0.018$, Table 6$)$.

\section{Discussion}

The reported incidence of upper gastrointestinal bleeding is still between 48 and 160 cases per 100,000 adults per year in the USA and other countries, reaching a $14 \%$ associated mortality, increased hospital admissions and hospitalization costs $[4,5]$. Peptic ulcer bleeding is seen predominantly among the elderly, with $68 \%$ of patients over the age of 60 and $27 \%$ over the age of 80 [5]. Elderly people with multiple comorbidities are often among those who fail endoscopic hemostasis and are poor candidates for surgery [7]. In a recent study, a large ulcer size was reported as an important independent re-bleeding risk factor. Ulcers of 10, 14, and $20 \mathrm{~mm}$ were associated with $17.7 \%, 20.6 \%$, and $24.1 \%$ re-bleeding rates. In a cohort of 1,264 patients with peptic ulcer bleeding, the reported 30-day re-bleeding rate was $17.7 \%$, surgical intervention was necessary for $6.7 \%$ and mortality reached $7.2 \%$ [8].

\section{TAE as alternative to surgery}

Prevention of re-bleeding is a challenging task, especially in a group of high-risk patients with NVUGIB. TAE has been proposed as an alternative to surgery when primary endoscopic he- mostasis fails, in particular in those patients who are high-risk candidates for surgery [4]. The reported success rate after TAE in the abovementioned study was up to $98 \%$. The recurrence of bleeding was $20 \%$, comparable with the results achieved after surgical intervention that is associated with $25-30 \%$ mortality, despite the fact that patients in the embolization group were older and with a prevalence of heart disease [4]. Thus, the current evidence supports two attempts at endoscopic control of active bleeding in most cases $[1,4,9]$.

\section{TAE vs. surgery}

In recent years, TAE has been increasingly used as an alternative to surgery in the upper NVUGIB refractory to endoscopic therapy. In a large study analyzing more than 1,500 hospital admissions, TAE or surgery was necessary for 5.4\% patients; half of them were operated on and another half underwent TAE, a significant part in preventive mode. The mortality rate was $12.5 \%$ after TAE and $25.6 \%$ after surgery, while the rebleeding rate was $25 \%$ after TAE and $16.3 \%$ after surgery. The authors conclude that TAE should be the preferred hemostatic method when endoscopy fails [10]. This method has been associated with a lower mortality and complication rate compared to surgery [10-12]. The choice of intervention in the case of re-bleeding after primary endoscopic hemostasis fails is still controversial. The reported mortality rate after two methods is comparable; however, the re-bleeding rate was reported to be higher after TAE $[13,14]$. In opposition, the results of the current study demonstrate the superiority of TAE in comparison with surgery, particularly considering that the median age of patients in our study was over 65 years and there were high risk patients with multiple comorbidities in both groups. Several authors have stressed the age factor and poor health as an

Table 4. Outcome Data

\begin{tabular}{llllll}
\hline & PE $+(\mathbf{N}=\mathbf{3 7})$ & PE- $(\mathbf{N}=\mathbf{7 4})$ & Pvalue & R & P value \\
\hline ICU, n $(\%)$ & $36(97 \%)$ & $59(81 \%)$ & 0.018 & 0.224 & 0.018 \\
ICU stay, days (IQR) & $3 /(4-2)$ & $3 /(5-2)$ & 0.981 & -0.009 & 0.932 \\
Hospital stay, days (IQR) & $7(12-6)$ & $8(12-7)$ & 0.067 & -0.175 & 0.066 \\
Mortality, n (\%) & $2(5 \%)$ & $8(11 \%)$ & 0.49 & -0.091 & 0.343 \\
\hline
\end{tabular}


Table 5. Binomial Multivariate Logistic Regression-Dependent Factor Re-Bleeding

\begin{tabular}{llll}
\hline Risk factor & Odds ratio & Confidance interval for OR & P value \\
\hline Rockall score & 0.967 & $0.705-1.327$ & 0.835 \\
HGB & 0.853 & $0.703-1.036$ & 0.109 \\
Endoscopic treatment & 0.741 & $0.418-1.316$ & 0.307 \\
Forrest classification & 1.247 & $0.697-2.233$ & 0.457 \\
Ulcer size & 0.507 & $0.997-1.001$ & 0.350 \\
INR & 0.507 & $0.138-1.863$ & 0.306 \\
\hline
\end{tabular}

argument against TAE $[13,14]$.

\section{In favor of TAE}

Different evidence comes from a number of other studies stressing a higher complication rate after surgery and better overall results after TAE [11]. The current experience with TAE even includes cases of endoscopically unmanageable bleeding [15-17], and the results are positive - TAE controlled acute NVUGIB effectively. TAE may be considered as a method with good long-term results when endoscopic therapy is unavailable or unsuccessful, and a correction of coagulopathy before TAE is recommended; still, re-bleeding may happen in about $10 \%$ of patients $[16,18-20]$. Although TAE has been recognized as a possible alternative to endoscopic therapy and surgery, experts have issued warnings that the performance of TAE should be trusted to more experienced specialists [20,21].

\section{Endoscopic factors}

Endoscopic diagnosis may not be possible on the first endoscopy in up to $24 \%$ of patients, usually due to excessive blood or clots obscuring the view. Because of that, the incidence of rebleeding may reach $55 \%$ with a subsequent $33 \%$ mortality rate [12]. Other criteria including the ulcer size of more than $20 \mathrm{~mm}$, localization in the stomach and oozing or spurting bleeding are recognized as important risk factors $[8,22]$, and negative angiography findings are associated with a lower re-bleeding rate than active bleeding with targeted embolization [23].

\section{Selection of patients for TAE}

The selection of patients who would benefit from preventive TAE is the most crucial task. The results of the current study are comparable with the criteria reported earlier of high risk NVUGIB $[5,7,8]$. Our patients had a median shock index $>$ 1 in both groups on admission and needed transfusion of, on average, four blood units.

\section{Risk factors and scores}

Risk assessment is an indisputable part of the management strategy in patients with acute gastrointestinal bleeding. Even considering the latest progress in endoscopic, surgical and interventional radiology, there is still a rather high rate of rebleeding - up to $20 \%$ - as well as deaths ranging from $5 \%$ to $10 \%$ particularly in unselected patients. Risk factor identification predicting a high risk of re-bleeding is one of the ways for outcome improvement in the patient group who are poor candidates for surgery $[8,11,12]$. Several criteria have been proposed for the stratification of high and low risk patients. The criteria include the physiologic response to bleeding: acute upper gastrointestinal bleeding and a substantial loss of intravascular volume, resting tachycardia, hypotension (systolic blood pressure, $<100 \mathrm{~mm} \mathrm{Hg}$ ), or postural changes (an increase in the pulse rate) and the importance of endoscopic findings (ulcer size and completeness of endoscopic hemostasis) [5, 8]. The Glasgow-Blatchford score is widely recommended for the prediction of outcomes and the timing of medical intervention including emergent endoscopy in patients with upper gastrointestinal bleeding [1, 9, 24-27]. The Rockall score is calculated based on the clinical variables indicating the urgency of endoscopic intervention and evidence of stigmata of bleeding $[5,28]$. The evidence of stigmata of bleeding complements the clinical Rockall score and adds a possibility to recognize patients who are at a high risk of re-bleeding after endoscopic intervention. The clinical Rockall score according to the author's definition [28] has a maximum value of 7 points, and according to a recent study is sensitive in the prediction of mortality; however, the Glasgow-Blatchford score

Table 6. Treatment Results in Patient Group with Median Rockall Score $\geq 7$

\begin{tabular}{llll}
\hline & PE + with Rockall score $\geq 7(\mathbf{N}=\mathbf{2 1})$ & PE- with Rockall score $\geq 7(\mathbf{N}=34)$ & P value \\
\hline Surgery, n (\%) & $0(0 \%)$ & $11(32 \%)$ & 0.004 \\
Re-bleeding, n (\%) & $1(4.8 \%)$ & $11(33 \%)$ & 0.018 \\
Hospital stay, days (IQR) & $7(11-5)$ & $9(13-7)$ & 0.063 \\
Mortality, n (\%) & $2(9.5 \%)$ & $6(18.2 \%)$ & 0.461 \\
\hline
\end{tabular}


Table 7. Risk Scoring Systems

\begin{tabular}{lll}
\hline Score & Efficacy & Authors \\
\hline Glasgow-Blatchford & Superior in predicting mortality and re-bleeding rate & $\begin{array}{l}\text { Camus et al, 2016 [8] } \\
\text { Martinez-Cara et al, 2016 [24] }\end{array}$ \\
Rockall & Superior in predicting mortality and re-bleeding rate & $\begin{array}{l}\text { Camus et al, 2016 [8] } \\
\text { Martinez-Cara et al, 2016 [24] }\end{array}$ \\
& & Rockall et al, 1996 [28] \\
AIMS65 & Similar to Glasgow-Blatchford and clinical Rockall score & Ratra et al, 2016 [30] \\
PNED & $\begin{array}{l}\text { Superior in the prediction of mortality in comparison with } \\
\text { the Rockall score, but was not validated externally }\end{array}$ & Stanley et al, 2017 [25] \\
& & Marmo et al, 2010 [29]
\end{tabular}

was more sensitive in the prediction of other outcomes, including the risk of re-bleeding [27]. Similar scoring systems were reported to be sensitive in the prognostication of high-risk patients and comparable with the Glasgow-Blatchford score when predicting in-patient mortality as well as predicting the need for endoscopic intervention [25, 29, 30] (Table 7). Still, the Glasgow-Blatchford score and the Rockall score are superior considering their sensitivity in predicting the re-bleeding rate $[8,24]$.

The results of the current study indicate that in the group of high risk patients who experienced re-bleeding episodes after emergent endoscopic hemostasis the most frequent endoscopic finding were the Forrest I-IIb type ulcers and the Rockall score $\geq 7$, which is consistent with the reports from literature. It also includes the observation that the patient's age of over 60 may be a risk factor. Patients from both groups who experienced rebleeding in our study had a median hemoglobin level of 8.2 $8.7 \mathrm{~g} / \mathrm{dL}$ before repeated hemostasis and needed transfusion of RBS and FFP in the amounts reported recently [8]. The majority of reports emphasize that patients undergoing a transarterial procedure for the evaluation and management of hemorrhage are often poor surgical candidates due to hemodynamic instability, comorbid conditions and coagulopathy $[1,2,7,8,13$, 14]. In the current study, the patient condition in both groups was quite similar before repeated hemostasis including the incidence of comorbid conditions, level of blood loss, shock index and coagulation status. There is evidence that in cases of severe gastrointestinal hemorrhage, the shock index is $>1$ [30], complying with the data from our study where the median shock index was $>1$ in both groups. Nevertheless, more studies are needed to acquire strong evidence. A recent international multicenter study, however, reported that no score seems accurate at predicting re-bleeding or the length of hospital stay, and further studies using these, or new scores, are required to clarify their role in directing the management of higher risk patients [25]. A 3.5-year prospective longitudinal study revealed that re-bleeding during the follow-up period was higher in patients with the Rockall score 2. Additional independent risk factors included disturbances of the clotting system and ASA physical status class [31]. The full Rockall score is better for 1-month mortality prediction while the Glasgow-Blatchford system is better for predicting other outcomes [27]. Contrary to what has been reported earlier, binominal multivariate logistic regression in our study did not reveal significant independent re-bleeding risk factors including the Rockall score.
However, in a subgroup of patients who underwent preventive TAE following primary endoscopic hemostasis, the Rockall score was 7 in the majority of patients and the same was evident in the patient group who did not undergo TAE indicating a high risk of re-bleeding in both groups. One patient experienced re-bleeding after preventive TAE and two died, resulting in a $9.5 \%$ mortality rate, yet no one required emergent surgical intervention. Very different results appeared in the comparison group with more than one-third of patients experiencing re-bleeding and more than one-third needing emergent surgical intervention, and the difference was significant - mortality reached $18.2 \%$. The strong points of our study are the routine assessment of the Glasgow-Blatchford and Rockall scores in the cases of gastrointestinal bleeding, and the availability of endoscopic and interventional radiology services on a 24-h basis, making the preventive TAE strategy for high risk elderly patients with comorbid conditions possible. However, a larger number of patients would add weight to the statistical analysis enabling the demonstration of stronger clinical evidence.

\section{Conclusion}

In this study, we revealed that the Rockall score $\geq 7$ could be a reliable predictor of re-bleeding after primary endoscopic hemostasis in a subgroup of high-risk elderly patients with NVUGIB and could serve as one of the criteria for the selection of indications for preventive TAE.

\section{Funding}

No funding to declare.

\section{Conflict of Interest}

We declare no conflict of interest.

\section{Author Contributions}

AK and GP conducted the research/study, analyzed the data, and wrote the manuscript. SP and PI performed the radiologic 
assessment and TAE. MM conducted the research/study and analyzed the data. AK designed the study and interpreted the results. All authors have read and approved the final manuscript.

\section{Abbreviations}

TAE: transarterial embolization; NVUGIB: non-variceal upper gastrointestinal bleeding; IQR: interquartile range; ICU: intensive care unit

\section{References}

1. Gralnek IM, Dumonceau JM, Kuipers EJ, Lanas A, Sanders DS, Kurien M, Rotondano G, et al. Diagnosis and management of nonvariceal upper gastrointestinal hemorrhage: European Society of Gastrointestinal Endoscopy (ESGE) Guideline. Endoscopy. 2015;47(10):a1-46.

2. Bratanic A, Puljiz Z, Ljubicicz N, Caric T, Jelicic I, Puljiz M, Perko Z. Predictive factors of rebleeding and mortality following endoscopic hemostasis in bleeding peptic ulcers. Hepatogastroenterology. 2013;60(121):112-117.

3. Loffroy RF, Abualsaud BA, Lin MD, Rao PP. Recent advances in endovascular techniques for management of acute nonvariceal upper gastrointestinal bleeding. World J Gastrointest Surg. 2011;3(7):89-100.

4. Barkun AN, Bardou M, Kuipers EJ, Sung J, Hunt RH, Martel M, Sinclair P, et al. International consensus recommendations on the management of patients with nonvariceal upper gastrointestinal bleeding. Ann Intern Med. 2010;152(2):101-113.

5. Gralnek IM, Barkun AN, Bardou M. Management of acute bleeding from a peptic ulcer. N Engl J Med. 2008;359(9):928-937.

6. Kaminskis A, Kratovska A, Ponomarjova S, Tolstova A, Mukans M, Stabina S, Gailums R, et al. Preventive transarterial embolization in upper nonvariceal gastrointestinal bleeding. World J Emerg Surg. 2017;12:3.

7. Laine L. CLINICAL PRACTICE. Upper gastrointestinal bleeding due to a peptic ulcer. N Engl J Med. 2016;374(24):2367-2376.

8. Camus M, Jensen DM, Kovacs TO, Jensen ME, Markovic D, Gornbein J. Independent risk factors of 30-day outcomes in 1264 patients with peptic ulcer bleeding in the USA: large ulcers do worse. Aliment Pharmacol Ther. 2016;43(10):1080-1089.

9. Greenspoon J, Barkun A. A summary of recent recommendations on the management of patients with nonvariceal upper gastrointestinal bleeding. Pol Arch Med Wewn. 2010;120(9):341-346.

10. Nykanen T, Peltola E, Kylanpaa L, Udd M. Bleeding gastric and duodenal ulcers: case-control study comparing angioembolization and surgery. Scand J Gastroenterol. 2017;52(5):523-530.

11. Wong TC, Wong KT, Chiu PW, Teoh AY, Yu SC, Au KW, Lau JY. A comparison of angiographic embolization with surgery after failed endoscopic hemostasis to bleeding peptic ulcers. Gastrointest Endosc. 2011;73(5):900-908.
12. Mirsadraee S, Tirukonda P, Nicholson A, Everett SM, McPherson SJ. Embolization for non-variceal upper gastrointestinal tract haemorrhage: a systematic review. Clin Radiol. 2011;66(6):500-509.

13. Beggs AD, Dilworth MP, Powell SL, Atherton H, Griffiths EA. A systematic review of transarterial embolization versus emergency surgery in treatment of major nonvariceal upper gastrointestinal bleeding. Clin Exp Gastroenterol. 2014;7:93-104.

14. Kyaw M, Tse Y, Ang D, Ang TL, Lau J. Embolization versus surgery for peptic ulcer bleeding after failed endoscopic hemostasis: a meta-analysis. Endosc Int Open. 2014;2(1):E6-E14.

15. Defreyne L, Vanlangenhove P, De Vos M, Pattyn P, Van Maele G, Decruyenaere J, Troisi R, et al. Embolization as a first approach with endoscopically unmanageable acute nonvariceal gastrointestinal hemorrhage. Radiology. 2001;218(3):739-748.

16. Yap FY, Omene BO, Patel MN, Yohannan T, Minocha J, Knuttinen MG, Owens CA, et al. Transcatheter embolotherapy for gastrointestinal bleeding: a single center review of safety, efficacy, and clinical outcomes. Dig Dis Sci. 2013;58(7):1976-1984.

17. Dixon S, Chan V, Shrivastava V, Anthony S, Uberoi R, Bratby $M$. Is there a role for empiric gastroduodenal artery embolization in the management of patients with active upper GI hemorrhage? Cardiovasc Intervent Radiol. 2013;36(4):970-977.

18. Eriksson LG, Ljungdahl M, Sundbom M, Nyman R. Transcatheter arterial embolization versus surgery in the treatment of upper gastrointestinal bleeding after therapeutic endoscopy failure. J Vasc Interv Radiol. 2008;19(10):1413-1418.

19. Ang D, Teo EK, Tan A, Ibrahim S, Tan PS, Ang TL, Fock KM. A comparison of surgery versus transcatheter angiographic embolization in the treatment of nonvariceal upper gastrointestinal bleeding uncontrolled by endoscopy. Eur J Gastroenterol Hepatol. 2012;24(8):929-938.

20. Lee HH, Park JM, Chun HJ, Oh JS, Ahn HJ, Choi MG. Transcatheter arterial embolization for endoscopically unmanageable non-variceal upper gastrointestinal bleeding. Scand J Gastroenterol. 2015;50(7):809-815.

21. Loffroy R, Abualsaud B, Cercueil JP, Krause D. Endoscopically unmanageable bleeding from duodenal ulcers: a job for the vascular surgeon or the interventional radiologist? Am J Surg. 2010;199(6):864-865; author reply 865-866.

22. Lau JY, Sung JJ, Lam YH, Chan AC, Ng EK, Lee DW, Chan FK, et al. Endoscopic retreatment compared with surgery in patients with recurrent bleeding after initial endoscopic control of bleeding ulcers. N Engl J Med. 1999;340(10):751-756.

23. Sildiroglu O, Muasher J, Arslan B, Sabri SS, Saad WE, Angle JF, Matsumoto AH, et al. Outcomes of patients with acute upper gastrointestinal nonvariceal hemorrhage referred to interventional radiology for potential embolotherapy. J Clin Gastroenterol. 2014;48(8):687-692.

24. Martinez-Cara JG, Jimenez-Rosales R, Ubeda-Munoz M, de Hierro ML, de Teresa J, Redondo-Cerezo E. Compari- 
son of AIMS65, Glasgow-Blatchford score, and Rockall score in a European series of patients with upper gastrointestinal bleeding: performance when predicting in-hospital and delayed mortality. United European Gastroenterol J. 2016;4(3):371-379.

25. Stanley AJ, Laine L, Dalton HR, Ngu JH, Schultz M, Abazi R, Zakko L, et al. Comparison of risk scoring systems for patients presenting with upper gastrointestinal bleeding: international multicentre prospective study. BMJ. 2017;356:i6432.

26. Bryant RV, Kuo P, Williamson K, Yam C, Schoeman MN, Holloway RH, Nguyen NQ. Performance of the Glasgow-Blatchford score in predicting clinical outcomes and intervention in hospitalized patients with upper GI bleeding. Gastrointest Endosc. 2013;78(4):576-583.

27. Mokhtare M, Bozorgi V, Agah S, Nikkhah M, Faghihi A, Boghratian A, Shalbaf N, et al. Comparison of GlasgowBlatchford score and full Rockall score systems to predict clinical outcomes in patients with upper gastrointestinal bleeding. Clin Exp Gastroenterol. 2016;9:337-343.

28. Rockall TA, Logan RF, Devlin HB, Northfield TC. Risk assessment after acute upper gastrointestinal haemorrhage. Gut. 1996;38(3):316-321.

29. Marmo R, Koch M, Cipolletta L, Capurso L, Grossi E, Cestari R, Bianco MA, et al. Predicting mortality in nonvariceal upper gastrointestinal bleeders: validation of the Italian PNED Score and Prospective Comparison with the Rockall Score. Am J Gastroenterol. 2010;105(6):12841291.

30. Ratra A, Rassameehiran S, Parupudi S, Nugent K. Utility of the shock index and other risk-scoring tools in patients with gastrointestinal bleeding. South Med J. 2016;109(3):178-184.

31. Yang EH, Cheng HC, Wu CT, Chen WY, Lin MY, Sheu BS. Peptic ulcer bleeding patients with Rockall Scores $>/=6$ are at risk of long-term ulcer rebleeding: a 3.5-year prospective longitudinal study. J Gastroenterol Hepatol. 2017. 